\title{
ASSOCIATIONS BETWEEN OVERWEIGHT/OBESITY AND PHYSICAL FITNESS VARIABLES IN KOREAN WOMEN
}

\author{
Jong-Hyuck Kim ${ }^{1}$, Wi-Young So ${ }^{2}$ \\ ${ }^{1}$ Department of Sport Education in Living, Bucheon University, Bucheon, Korea \\ ${ }^{2}$ Department of Human Movement Science, Seoul Women's University, Seoul, Korea
}

\begin{abstract}
SUMMARY
Aim: The purpose of this study was to investigate whether physical fitness variables are related to overweight or obesity in Korean women.

Methods: From 2007 to 2011, 10,790 women aged 20-82 years visited a public health centre for evaluation of cardiovascular function, healthrelated physical fitness, and motor-related physical fitness. We used the definitions of overweight and obesity provided in the World Health Organization's Asia-Pacific Standard Report. Cardiovascular function was evaluated using the Resting Heart Rate (RHR) and vital capacity. Health-related physical fitness was evaluated using the $\mathrm{VO}_{2}$ max measure, sit-up number, grip strength, and sit-and-reach distance. Motor-related physical fitness was evaluated using the vertical-jump distance, side-step number, and balance (standing on 1 foot with eyes open) measure.

Results: The prevalence rates of overweight and obesity were $26.9 \%$ and $28.8 \%$, respectively. Results are presented as odds ratios (with $95 \%$ confidence intervals) after adjusting for age and number of alcoholic drinks consumed per week, cigarettes smoked per day, and exercise sessions per week. When RHR increased by 1 beat per minute, overweight prevalence was 1.012 times higher $(1.007-1.017, p<0.001)$ and obesity prevalence was 1.006 times higher $(1.000-1.011, \mathrm{p}=0.037)$. When $\mathrm{VO}_{2}$ max increased by $1 \mathrm{~mL}^{\mathrm{kg}} \mathrm{kg}^{-1} . \mathrm{min}^{-1}$, overweight was 0.949 times less prevalent $(0.939-0.959, p<0.001)$, and obesity was 0.916 times less prevalent $(0.906-0.926, p<0.001)$. As grip strength increased, overweight prevalence and obesity prevalence increased. An increase in vertical-jump distance by $1 \mathrm{~cm}$ was accompanied by a decrease in overweight prevalence by a factor of $0.975(0.967-0.982, p<0.001)$ and a decrease in obesity prevalence by a factor of $0.940(0.932-0.948, p<0.001)$.

Conclusion: Overweight and obesity were associated with poor physical fitness as assessed by variables related to cardiovascular function and health-related and motor-related physical fitness.
\end{abstract}

Key words: obesity, cardiovascular function, health-related physical fitness, motor-related physical fitness

Address for correspondence: Wi-Young So, Department of Human Movement Science, Seoul Women's University, Seoul, Korea. E-mail: wowso@swu.ac.kr

\section{INTRODUCTION}

According to the 2011 Korea National Health and Nutrition Examination Survey V-2 (KNHANES V-2), 35.1\% of Korean men and $27.1 \%$ of Korean women older than 19 years are obese, and the prevalence of obesity is increasing each year (1). Furthermore, the World Health Organization (WHO) reported that 1.4 billion adults older than 20 years were overweight, including more than 200 million obese men and nearly 300 million obese women. In 2008 , more than $10 \%$ of the global adult population was obese (2).

Because obesity is a major risk factor for chronic diseases such as cardiovascular disease (mainly heart disease and stroke), type 2 diabetes, musculoskeletal disorders (especially osteoarthritis), and some cancers, the high prevalence of obesity is becoming a major global public health and socioeconomic problem (2-4). Therefore, many studies have investigated strategies for the treatment and prevention of excess weight gain that involve decreasing energy consumption (through reduced salt and sugar intake) and increasing physical activity and exercise (5-9).

Compared to normal-weight individuals, obese people generally have lower levels of physical fitness (10). Moreover, poor physical fitness is associated with a higher prevalence of chronic diseases such as coronary artery disease and metabolic syndrome, resulting in higher overall mortality rates (11-13). Therefore, excess weight is a major risk factor for poor fitness, chronic disease and death.

There are 2 types of physical fitness: health-related and motorrelated fitness (14). Health-related physical fitness comprises cardiorespiratory endurance, muscular endurance, muscular strength, and flexibility. Motor-related physical fitness comprises power, agility and balance (14). Even though physical fitness variables are diversely classified, previous researchers have generally used cardiorespiratory endurance $\left(\mathrm{VO}_{2} \mathrm{max}\right)$ to assess physical fitness (15), and we agree that the measure of $\mathrm{VO}_{2}$ max is the gold standard for assessing physical fitness. However, several physical fitness variables are used in the field of exercise prescription, and it is very important to establish the relationship between obesity and these other variables.

So and Choi and So et al. recently investigated whether values of health-related and motor-related physical fitness variables are poorer in obese people than in normal-weight people (16-17). However, a major limitation of these studies was that they simply compared each group's significant differences using one-way 
analysis of variance (ANOVA) and a post-hoc test. This analysis only determined whether differences occurred between groups. It did not provide information about the prevalence of obesity in a group whose physical fitness was poorer than that of normalweight individuals. Therefore, to take this research further, we conducted this study to investigate the relationships between physical fitness variables and obesity by using multiple logistic regression analyses and provide more detailed information for use in exercise prescription. Furthermore, cardiovascular function can be used indirectly to evaluate physical performance for the purpose of exercise prescription. By examining the association between cardiovascular function and prevalence of overweight and obesity, we aimed to increase the usefulness of our research.

\section{MATERIALS AND METHODS}

\section{Subjects}

From January 1, 2007 to November 30, 2011, 10,790 women aged 20-82 years visited a public health centre in Y-gu in Seoul, Korea. Their cardiovascular function, health-related physical fitness, and motor-related physical fitness were assessed. They provided written consent to participate in this study and all the study procedures were approved by the Human Care and Use Committee of the Y-gu Community Health Centre. Characteristics of the subjects are summarized in Table 1.

\section{Experimental Procedures}

The subjects were categorized on the basis of self-reported data. Three smoking categories were defined: non-smoking, smoking $<1$ pack of cigarettes per day, and smoking $\geq 1$ pack of cigarettes per day. Three categories of alcohol consumption were defined: no alcohol consumption, consumption of 1-2 drinks per week, and consumption of $\geq 3$ drinks per week. Three exercise groups were defined, according to frequency of exercise training: no exercise, exercise for 1-2 times per week, and exercise for $\geq 3$ times per week.

Height and weight were measured with Inbody-720 (Biospace; Seoul, Korea), while patients wore a light gown. BMI (kg. $\left.\mathrm{m}^{-2}\right)$ was calculated from the height and weight. According to the WHO Asia-Pacific Standard of Obesity, subjects with BMI $<23 \mathrm{~kg} \cdot \mathrm{m}^{-2}$, $\geq 23 \mathrm{~kg} \cdot \mathrm{m}^{-2},<25 \mathrm{~kg} \cdot \mathrm{m}^{-2}$, and $\geq 25$ were classified as normal weight, overweight, and obese, respectively (18).

Cardiovascular function was evaluated by measuring resting heart rate (RHR) and vital capacity. After filling in a questionnaire, the subjects rested for more than $10 \mathrm{~min}$ in the sitting position. RHR was measured for an average duration of 1 min with a heart-rate sensor (Polar-S610; Finland) worn on the chest. For measurement of maximum exhalation volume (in liters), subjects attached the pneumatic sensor of a vital capacity-measuring instrument (Helmas-SH-9600C; Korea) to their mouth, inhaled deeply, and then exhaled.

Health-related physical fitness was evaluated as cardiorespiratory endurance, muscular endurance, muscular strength, and

Table 1. Characteristics of 10,790 normal-weight, overweight, and obese Korean women (mean $\pm S D$ or N \%)

\begin{tabular}{|c|c|c|c|c|}
\hline Category & Variable & $\begin{array}{l}\text { Normal } \\
(\mathrm{N}=4,779)\end{array}$ & $\begin{array}{l}\text { Overweight } \\
(\mathrm{N}=2,906)\end{array}$ & $\begin{array}{c}\text { Obese } \\
(\mathrm{N}=3,105)\end{array}$ \\
\hline \multirow[t]{4}{*}{ Anthropometry } & Age (y) & $44.90 \pm 10.53$ & $49.07 \pm 9.93$ & $50.75 \pm 10.25$ \\
\hline & Height (cm) & $157.74 \pm 5.33$ & $156.68 \pm 5.63$ & $156.00 \pm 5.85$ \\
\hline & Weight (kg) & $52.91 \pm 4.70$ & $58.87 \pm 4.45$ & $66.27 \pm 7.01$ \\
\hline & Body mass index $\left(\mathrm{kg} / \mathrm{m}^{2}\right)$ & $21.24 \pm 1.32$ & $23.95 \pm 0.57$ & $27.19 \pm 1.97$ \\
\hline \multirow[t]{2}{*}{ Cardiovascular function } & Resting heart rate (beats/min) & $73.80 \pm 8.76$ & $74.79 \pm 9.36$ & $74.23 \pm 10.05$ \\
\hline & Vital capacity (L) & $2.83 \pm 0.58$ & $2.74 \pm 0.61$ & $2.71 \pm 0.63$ \\
\hline \multirow[t]{4}{*}{ Health-related physical fitness } & $\mathrm{VO}_{2} \max \left(\mathrm{mL} \cdot \mathrm{kg}^{-1} \cdot \mathrm{min}^{-1}\right)$ & $27.69 \pm 5.14$ & $26.04 \pm 4.99$ & $25.06 \pm 5.21$ \\
\hline & Sit-ups (reps/min) & $13.79 \pm 5.53$ & $12.80 \pm 5.83$ & $11.90 \pm 6.06$ \\
\hline & Grip strength (kg) & $27.93 \pm 4.06$ & $28.06 \pm 4.66$ & $28.62 \pm 5.25$ \\
\hline & Sit-and-reach $(\mathrm{cm})$ & $17.85 \pm 7.81$ & $17.50 \pm 7.07$ & $14.23 \pm 9.02$ \\
\hline \multirow[t]{3}{*}{ Motor-related physical fitness } & Vertical jump (cm) & $25.97 \pm 7.44$ & $23.33 \pm 7.32$ & $21.42 \pm 7.12$ \\
\hline & Side steps (reps/30 s) & $31.86 \pm 5.42$ & $30.30 \pm 5.32$ & $28.64 \pm 5.60$ \\
\hline & Balance $^{a}(s)$ & $48.71 \pm 40.14$ & $38.78 \pm 36.02$ & $29.76 \pm 30.32$ \\
\hline \multirow[t]{3}{*}{ Cigarettes per day } & Non-smoking & $4,686(98.0 \%)$ & $2,844(97.9 \%)$ & $3,014(97.0 \%)$ \\
\hline & $<1$ pack of cigarettes per day & $79(1.7 \%)$ & $50(1.7 \%)$ & $67(2.2 \%)$ \\
\hline & $\geq 1$ pack of cigarettes per day & $14(0.3 \%)$ & $12(0.4 \%)$ & $24(0.8 \%)$ \\
\hline \multirow[t]{3}{*}{ Alcoholic drinks per week } & Non-drinking & $4,163(87.1 \%)$ & $2,461(84.7 \%)$ & $2,638(85.0 \%)$ \\
\hline & 1-2 drinks per week & $534(11.2 \%)$ & $371(12.8 \%)$ & $363(11.7 \%)$ \\
\hline & $\geq 3$ drinks per week & $82(1.7 \%)$ & $74(2.5 \%)$ & $104(3.3 \%)$ \\
\hline \multirow[t]{3}{*}{ Exercise sessions per week } & No-exercise & $2,243(46.9 \%)$ & $1,384(47.6 \%)$ & $1,513(48.7 \%)$ \\
\hline & 1-2 times per week & $1,424(29.8 \%)$ & $970(33.4 \%)$ & $1,028(33.1 \%)$ \\
\hline & $\geq 3$ times per week & $1,112(23.3 \%)$ & $552(19.0 \%)$ & $564(18.2 \%)$ \\
\hline
\end{tabular}

aStanding on 1 foot with eyes open 
flexibility as parameters of $\mathrm{VO}_{2} \max \left(\mathrm{mL} \cdot \mathrm{kg}^{-1} \cdot \mathrm{min}^{-1}\right)$, number of sit-ups in $1 \mathrm{~min}$, grip strength $(\mathrm{kg})$, and sit-and-reach distance (cm), respectively.

$\mathrm{VO}_{2}$ max was measured according to the YMCA submaximal test, using a cycle ergometer (Helmas-SH-9600K; Korea) (19). $\mathrm{VO}_{2} \max$ was estimated by gradually increasing the exercise intensity, starting at $150 \mathrm{~kg} \cdot \mathrm{m}^{-1}$, for $3 \mathrm{~min}$, for which the PolarS610 heart rate monitor system (Finland) was used. For sit-ups, the subjects were instructed to lie on a sit-up board (Helams-SH$9600 \mathrm{~N}$; Korea), bend their knees to $90^{\circ}$, raise their upper body, and bend forward using only their abdominal muscles. The number of sit-ups completed in $1 \mathrm{~min}$ was recorded. For grip strength, the control lever of a grip-strength tester (Helmas-SH-9600D; Korea) equipped with a potentiometer control system was adjusted such as the second knuckle of the fingers was at the bottom of the grip bar. The subjects flexed maximally during 3 trials, and the average value of grip strength $(\mathrm{kg})$ was recorded. For the sit-andreach test, the subjects sat on a flexibility-measuring instrument (Helmas-SH-9600G; Korea), spread their heels approximately 5 $\mathrm{cm}$ apart, brought their heels to the edge, extended their knees straight, bended their back forward, and naturally made the measuring instrument board move forward. The average result of 3 trials was recorded.

Motor-related physical fitness was evaluated as power, agility, and balance as parameters of vertical-jump distance $(\mathrm{cm})$, number of side-steps in $30 \mathrm{~s}$, and balance (standing on 1 foot with eyes open, $s$ ).

For vertical jump, subjects were instructed to jump as high as possible from a vertical-jump board (Helmas-SH-9600F; Korea). The height they jumped was measured in centimeters, and the average value of 3 trials was recorded. For side steps, the subjects were instructed to stand with both feet on the centerline of a long board with $100-\mathrm{cm}$-long parallel lines on both sides (HelmasSH-9600J; Korea). The subjects crossed the line on the right, returned to the centerline, crossed the line on the left, and then returned to the original position on the centerline. We counted the number of times the subjects crossed the line during $30 \mathrm{~s}$. For the balance test, subjects stood on 1 leg (the leg they preferred) on a balance-measuring instrument (Helmas-SH-9600H; Korea) and kept their eyes open and both hands on their waist. We measured the time until the elevated leg touched either the other leg or the ground, or until both hands dropped; the average result of 3 trials was recorded. These physical fitness tests followed the recommendations in the book Advanced Fitness Assessment and Exercise Prescription (14).

\section{Statistical Analysis}

All results are presented as means $\pm \mathrm{SD}$. Multiple logistic regression analyses were conducted to evaluate (1) the association of cardiovascular function and physical fitness with overweight, and (2) the association of cardiovascular function and physical fitness with obesity after adjusting for age and number of alcoholic drinks consumed per week, cigarettes smoked per day, and exercise sessions per week. All analyses were performed using SPSS software version 12.0 (SPSS; Chicago, IL, USA). A p value $<0.05$ was considered statistically significant.

\section{RESULTS}

The results of multiple logistic regression analyses are shown in Table 2.

For cardiovascular function, when RHR increased by 1 beat per minute, overweight prevalence was 1.012 times higher $(1.007-1.017, \mathrm{p}<0.001)$ and obesity prevalence was 1.006 times higher $(1.000-1.011, \mathrm{p}=0.037)$. As vital capacity increased by $1 \mathrm{~L}$, overweight prevalence decreased by a factor of 0.898

Table 2. Multiple logistic regression analyses for cardiovascular function and physical fitness in Korean women according to weight status $(N=10,790)$

\begin{tabular}{|c|c|c|c|c|c|c|c|c|c|c|c|}
\hline \multirow{2}{*}{ Category } & \multirow{2}{*}{ Variable } & \multicolumn{5}{|c|}{ Normal weight vs. overweight } & \multicolumn{5}{|c|}{ Normal weight vs. obese } \\
\hline & & B & SE & OR & $95 \% \mathrm{Cl}$ & $p$ & B & SE & OR & $95 \% \mathrm{Cl}$ & $\mathrm{p}$ \\
\hline \multirow[t]{2}{*}{$\begin{array}{l}\text { Cardiovascular } \\
\text { function }\end{array}$} & $\begin{array}{l}\text { Resting heart } \\
\text { rate (beats } / \mathrm{min} \text { ) }\end{array}$ & 0.012 & 0.003 & 1.012 & $1.007-1.017$ & $<0.001^{* * *}$ & 0.005 & 0.003 & 1.006 & $1.000-1.011$ & $0.037^{\star}$ \\
\hline & Vital capacity $(L)$ & -0.108 & 0.042 & 0.898 & $0.826-0.976$ & $0.011^{*}$ & -0.135 & 0.042 & 0.874 & $0.805-0.949$ & $0.001^{* *}$ \\
\hline \multirow{4}{*}{$\begin{array}{l}\text { Health-related } \\
\text { physical fit- } \\
\text { ness }\end{array}$} & $\begin{array}{l}\mathrm{VO}_{2} \max \\
\left(\mathrm{mL} \cdot \mathrm{kg}^{-1} \cdot \mathrm{min}^{-1}\right)\end{array}$ & -0.052 & 0.005 & 0.949 & $0.939-0.959$ & $<0.001^{* * *}$ & -0.088 & 0.006 & 0.916 & $0.906-0.926$ & $<0.001^{* * *}$ \\
\hline & $\begin{array}{l}\text { Sit-ups (reps/ } \\
\text { min) }\end{array}$ & -0.012 & 0.005 & 0.988 & $0.978-0.997$ & $0.009^{* *}$ & -0.034 & 0.005 & 0.967 & $0.958-0.976$ & $<0.001^{* \star *}$ \\
\hline & $\begin{array}{l}\text { Grip strength } \\
(\mathrm{kg})\end{array}$ & 0.025 & 0.006 & 1.026 & $1.014-1.037$ & $<0.001^{* * *}$ & 0.058 & 0.006 & 1.060 & $1.048-1.071$ & $<0.001^{* \star *}$ \\
\hline & $\begin{array}{l}\text { Sit-and-reach } \\
(\mathrm{cm})\end{array}$ & -0.007 & 0.003 & 0.993 & $0.987-0.999$ & $0.034^{*}$ & -0.052 & 0.003 & 0.949 & $0.944-0.955$ & $<0.001^{* * *}$ \\
\hline Motor-related & $\begin{array}{l}\text { Vertical jump } \\
\text { (cm) }\end{array}$ & -0.026 & 0.004 & 0.975 & $0.967-0.982$ & $<0.001^{* * *}$ & -0.062 & 0.004 & 0.940 & $0.932-0.948$ & $<0.001^{* * *}$ \\
\hline \multirow[t]{2}{*}{$\begin{array}{l}\text { Physical } \\
\text { fitness }\end{array}$} & $\begin{array}{l}\text { Side steps } \\
\text { (reps/30 s), }\end{array}$ & -0.021 & 0.006 & 0.980 & $0.969-0.991$ & $<0.001^{* * *}$ & -0.064 & 0.006 & 0.938 & $0.927-0.948$ & $<0.001^{* * *}$ \\
\hline & Balance $^{\dagger}(\mathrm{s})$ & -0.003 & 0.001 & 0.997 & $0.996-0.999$ & $<0.001^{* * *}$ & -0.010 & 0.001 & 0.990 & $0.988-0.992$ & $<0.001^{* * *}$ \\
\hline
\end{tabular}

${ }^{*} p<0.05 ;{ }^{* *} p<0.01 ;{ }^{* * *} p<0.001$ (Adjusted for age, alcoholic drinks per week, cigarettes per day, and exercise sessions per week)

tStanding on 1 foot with eyes open 
$(0.826-0.976, \mathrm{p}=0.011)$ and obesity prevalence decreased by a factor of $0.874(0.805-0.949, \mathrm{p}=0.001)$.

For health-related physical fitness, when $\mathrm{VO}_{2}$ max increased by $1 \mathrm{~mL} \cdot \mathrm{kg}^{-1} \cdot \mathrm{min}^{-1}$, overweight was 0.949 times less prevalent $(0.939-0.959, \mathrm{p}<0.001)$ and obesity was 0.916 times less prevalent $(0.906-0.926, \mathrm{p}<0.001)$. When the number of sit-ups increased by 1 repetition. min $^{-1}$, overweight was 0.988 times less prevalent $(0.978-0.997, \mathrm{p}=0.009)$, and obesity was 0.967 times less prevalent $(0.958-0.976, \mathrm{p}<0.001)$. As grip strength increased by $1 \mathrm{~kg}$, overweight prevalence was 1.026 times higher (1.014$1.037, \mathrm{p}<0.001)$ and obesity prevalence was 1.060 times higher (1.048-1.071, $\mathrm{p}<0.001)$. As sit-and-reach distance increased by $1 \mathrm{~cm}$, overweight prevalence decreased by a factor of 0.993 (0.987-0.999, $\mathrm{p}=0.034)$ and obesity prevalence decreased by a factor of $0.949(0.944-0.955, \mathrm{p}<0.001)$.

With regard to motor-related physical fitness, as vertical-jump distance increased by $1 \mathrm{~cm}$, overweight prevalence decreased by a factor of $0.975(0.967-0.982, \mathrm{p}<0.001)$ and obesity prevalence decreased by a factor of $0.940(0.932-0.948, \mathrm{p}<0.001)$. When the number of side steps increased by 1 repetition per $30 \mathrm{~s}$, overweight prevalence was 0.980 times lower $(0.969-0.991, \mathrm{p}<0.001)$ and obesity prevalence was 0.938 times lower $(0.927-0.948, \mathrm{p}<0.001)$. When the time for standing on 1 foot with eyes open increased by $1 \mathrm{~s}$, overweight prevalence decreased by a factor of 0.997 $(0.996-0.999, \mathrm{p}<0.001)$ and obesity prevalence by a factor of $0.990(0.988-0.992, \mathrm{p}<0.001)$.

\section{DISCUSSION}

We hypothesize that as overweight increases, body movements become slower negatively affecting daily physical activities due to which obese people form and maintain a habit of working while seated, which reduces their physical fitness. However, previous studies that investigated the association between obesity and physical fitness used only 1 parameter of physical fitness, namely, $\mathrm{VO}_{2} \max$, a measurement of cardiorespiratory endurance $(10,15)$. We sought to incorporate diverse physical fitness variables that are used in the field of exercise prescription, including measurements of cardiovascular function, and compare these parameters among overweight, obese, and normal-weight people.

The results of this study show that overweight and obesity are associated with poorer physical fitness with regard to all the variables assessed, despite adjustments for obesity-related covariate variables. Although previous studies were limited to investigating only 1 or 2 categories of physical fitness $(10,15$, 20 ), our results are consistent with the results of these studies: compared to normal-weight people, obese people have poorer physical fitness. We confirmed that obese people not only have lower $\mathrm{VO}_{2} \max$ (cardiorespiratory endurance), but also poorer levels of other physical fitness variables.

Interestingly, Jetté et al. found that as BMI increase in obese people, muscular endurance decreases, but muscular strength increases (21). This finding shows that although excess weight is a physical burden in daily life, obese people can maintain relatively high levels of muscular strength. Although body composition was not directly measured in our study, we believe that the results may reflect the role of increased absolute fat-free mass in obese people. Nevertheless, too little daily activity may result in low muscular endurance. This research also supports the conclusion that, compared with normal-weight people, obese people have greater muscular strength but lower muscular endurance. Carefully designed studies are required to determine the extent to which muscular strength is affected by overweight or obesity.

Our study had several limitations. First, because of its retrospective design, we did not establish cause-and-effect relationships but only identified associations between overweight/obesity and physical fitness variables. Second, because all the subjects were women, the associations identified might be different in men. Third, the subjects were recruited from 1 public health center in Seoul, Korea, and cannot represent the general population of South Korea. However, we think that the large number of subjects $(\mathrm{N}=10,790)$ is one of the greatest strengths of this study. Future studies are required to identify and describe the relationships between overweight or obesity and physical fitness variables.

In conclusion, overweight or obesity is associated with poorer levels of physical fitness as measured by variables related to cardiovascular function, health-related physical fitness, and motor-related physical fitness.

\section{Acknowledgement}

This work was supported by a special research grant from Seoul Women's University (2013).

\section{Conflict of Interests}

None declared

\section{REFERENCES}

1. Korea Centers for Disease Control and Prevention. Korea health statistics 2011: Korea National Health and Nutrition Examination Survey (KNHANES V-2). Seoul: Korea Centers for Disease Control and Prevention; 2012.

2. World Health Organisation [Internet]. Geneva: WHO; 2012. Global Strategy on Diet, Physical Activity and Health; [cited 2013 Feb 01]. Available from: http://www.who.int/mediacentre/factsheets/fs311/en/.

3. Wadden TA, Stunkard AJ. Handbook of obesity treatment. 3rd ed. New York: Guilford Press; 2002.

4. Vangelova K, Deyanov C. Dyslipoproteinemias in industrial workers: relationship with hypertension and overweight. Cent Eur J Public Health. 2000 May;8(2):77-9.

5. Qin L, Knol MJ, Corpeleijn E, Stolk RP. Does physical activity modify the risk of obesity for type 2 diabetes: a review of epidemiological data. Eur J Epidemiol. 2010;25(1):5-12.

6. Bodor JN, Rice JC, Farley TA, Swalm CM, Rose D. The association between obesity and urban food environments. J Urban Health. 2010 Sep;87(5):771-81.

7. Vitáriušová E, Babinská K, Koštálová L, Rosinský J, Hlavatá A, Pribilincová Z, et al. Food intake, leisure time activities and the prevalence of obesity in schoolchildren in Slovakia. Cent Eur J Public Health. 2010 Dec;18(4):192-7.

8. Humeníková L, Gates GE. Dietary intakes, physical activity, and predictors of child obesity among 4-6th graders in the Czech Republic. Cent Eur J Public Health. 2007 Mar;15(1):23-8.

9. Ostrowska L, Lech MM. The effectiveness of a body mass reduction program in obese women in perimenopausal and menopausal age compared with the effectiveness of such a program in younger (18-44 years of age) women living in Poland. Cent Eur J Public Health. 2005 Mar;13(1):40-6.

10. Wei M, Kampert JB, Barlow CE, Nichaman MZ, Gibbons LW, Paffenbarger RS Jr, et al. Relationship between low cardiorespiratory fitness and mortality in normal-weight, overweight, and obese men. JAMA. 1999 Oct 27;282(16):1547-53.

11. Pedersen BK. Body mass index-independent effect of fitness and physical activity for all-cause mortality. Scand J Med Sci Sports. 2007 Jun;17(3):196-204. 
12. Adamu B, Sani MU, Abdu A. Physical exercise and health: a review. Niger J Med. 2006 Jul-Sep;15(3):190-6.

13. Lee J, Kim SU, Kang HS. Low cardio/respiratory fitness as an independent predictor of metabolic syndrome in Korean young men. Eur J App Physiol. 2010 Mar;108(4):633-9.

14. Heyward VH. Advanced fitness assessment and exercise prescription. 6th ed. Champaign (IL): Human Kinetics; 2010.

15. Blair SN, Cheng Y, Holder JS. Is physical activity or physical fitness more important in defining health benefits? Med Sci Sports Exerc. 2001 Jun;33(6 Suppl):S379-99.

16. So WY, Choi DH. Differences in physical fitness and cardiovascular function depend on BMI in Korean men. J Sports Sci Med. 2010 Jun;9(2):23944.

17. So WY, Seo DI, Choi DH. BMI differences according to fitness and cardiovascular function in Korean women. HealthMed. 2011;5(5):1137-44
18. WHO/IASO/IOTF. The Asia-Pacific perspective: redefining obesity and its treatment. Melbourne: Health Communications Australia; 2000.

19. Golding LA. YMCA fitness testing and assessment manual. 4th ed. Champaign (IL): Human Kinetics; 2000.

20. Meyers DA, Goldberg AP, Bleecker ML, Coon PJ, Drinkwater DT, Bleecker ER. Relationship of obesity and physical fitness to cardiopulmonary and metabolic function in healthy older men. J Gerontol. 1991 Mar;46(2):M57-65.

21. Jetté M, Sidney K, Lewis W. Fitness, performance and anthropometric characteristics of 19,185 Canadian Forces personnel classified according to body mass index. Mil Med. 1990 Mar;155(3):120-6.

Received August 14, 2012 Accepted in revised form February 1, 2013 